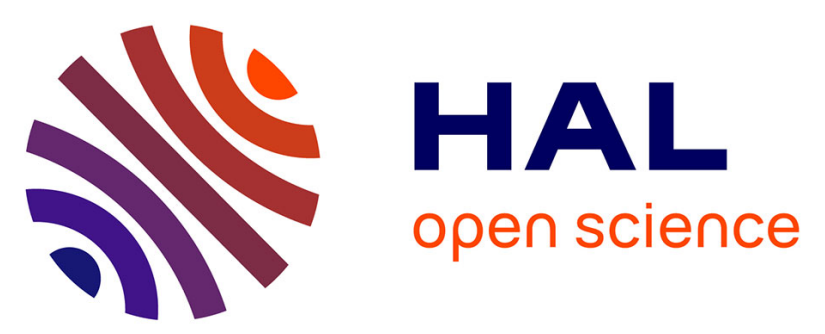

\title{
High power femtosecond chirped pulse amplification in large mode area photonic bandgap Bragg fibers
}

Louis Daniault, Dmitry Gaponov, Marc Hanna, Sébastien Février, Philippe Roy, Frédéric Druon, Patrick Georges, M.E. Likhachev, M.Y. Salganskii, M.V. Yashkov

\section{To cite this version:}

Louis Daniault, Dmitry Gaponov, Marc Hanna, Sébastien Février, Philippe Roy, et al.. High power femtosecond chirped pulse amplification in large mode area photonic bandgap Bragg fibers. Applied Physics B - Laser and Optics, 2011, 103, pp.615-621. 10.1007/s00340-011-4446-y . hal-00618229

\section{HAL Id: hal-00618229 https://hal.science/hal-00618229}

Submitted on 1 Sep 2011

HAL is a multi-disciplinary open access archive for the deposit and dissemination of scientific research documents, whether they are published or not. The documents may come from teaching and research institutions in France or abroad, or from public or private research centers.
L'archive ouverte pluridisciplinaire HAL, est destinée au dépôt et à la diffusion de documents scientifiques de niveau recherche, publiés ou non, émanant des établissements d'enseignement et de recherche français ou étrangers, des laboratoires publics ou privés. 


\title{
High power femtosecond chirped pulse amplification in large mode area
}

\section{photonic bandgap Bragg fibers}

\author{
Louis Daniault ${ }^{1}$, Dmitry A. Gaponov ${ }^{2}$, Marc Hanna ${ }^{1}$, Sébastien Février ${ }^{2}$, Philipple Roy ${ }^{2}$, Frédéric \\ Druon $^{1}$, Patrick Georges ${ }^{1}$, Mikhail E. Likhachev $^{3}$, Mikhail Yu. Salganskii $^{4}$, Mikhail V. Yashkov $^{4}$ \\ ${ }^{1}$ Laboratoire Charles Fabry de l'Institut d'Optique, CNRS, Université Paris-Sud, 91127 Palaiseau, France \\ 2 Xlim, UMR 6172 CNRS - University of Limoges, 123 Avenue A. Thomas, 87060 Limoges cedex, France \\ ${ }^{3}$ Fiber Optics Research Center of Russian Academy of Sciences, 38 Vavilov Street, Moscow, 119333, Russia \\ ${ }^{4}$ Institute of Chemistry of High Purity Substances, 49 Tropinin Street, Nizhny Novgorod, 603950, Russia
}

Received: date / Revised version: date

\begin{abstract}
We report on high power amplification of femtosecond pulses in 40- $\mu \mathrm{m}$ core diameter $\mathrm{Yb}$-doped photonic bandgap Bragg fibers. The robustness to bending and transverse spatial behavior of these fibers is analyzed through simulations. The fibers are used in both stages of a moderately stretched (150 ps) femtosecond chirped pulsed amplification (CPA) system. A compressed average power of $6.3 \mathrm{~W}$ is obtained using a lowindex polymer-coated Bragg fiber with excellent beam quality and high efficiency, in agreement with numerical simulations. The use of an air-clad Bragg fiber allows us to scale the output power to $47 \mathrm{~W}$ at a repetition rate of $35 \mathrm{MHz}$. This experiment demonstrates the great potential of Bragg fibers to increase the mode area
\end{abstract} and the power of practical bending-tolerant femtosecond fiber systems.

\section{Introduction}

The use of ytterbium-doped fibers to amplify femtosecond pulses is now widely recognized as an alternative solution to bulk systems, especially for high-average power systems [1]. Indeed, for fibers a few meters in length, the high surface-to-volume ratio induces an excellent thermal handling capability, allowing the generation of high average power radiation at high repetition rates. Moreover, the spectral gain of ytterbium ions in silica glass is wide enough $(40 \mathrm{~nm})$ to produce pulses a few hundred femtoseconds in duration [2]. Finally, if the fiber is 
operated in conditions such that only one single transverse mode is efficiently amplified, the spatial profile of the amplified beam can be diffraction-limited. However, the high electric field associated with the long lasermatter interaction length leads to strong third-order optical nonlinearities. Therefore, in a fiber amplifier, the temporal and spectral shapes can be strongly deteriorated in an irreversible manner. The most common techniques to reduce the level of nonlinear effects consist in spreading the optical intensity both in time, using the Chirped-Pulse Amplification (CPA) technique [3], and in space, using Large Mode Area (LMA) fibers.

For structures guiding by means of the total internal reflection mechanism, increasing the core size, other things being equal, makes the fiber multimode. This effect can be overcome by finely tuning the index contrast between the core and the cladding, for example using the microstructured fiber technology [4]. Using this technique, fibers with core of several tens of microns in diameter were produced. These fibers are however very weakly guiding structures, and are therefore very sensitive to bending-induced loss and beam distortion, hence the concept of rod-type fiber, that has led to core diameters as large as $100 \mu \mathrm{m}$ [5]. The presence of air holes in these fibers induces practical handling difficulties for splicing, cleaving, preparing fiber facets, etc.

All-silica two-dimensional photonic bandgap fibers [6], that can be doped with rare-earth ions, have been used recently for intra-cavity distributed spectral filter- ing. The inherent spectral filtering capabilities have allowed efficient amplification from an Yb-doped PBGF at either 980-nm [7] or 1180-nm [8].

As an alternative we have recently proposed the allsolid photonic bandgap Bragg fiber (BF) design [9]. Due to its different waveguiding mechanism, this type of fiber offers a very flexible geometry for designing waveguide structures with properties such as LMA $[9,10]$, polarization maintaining [11], and low bending sensitivity [12]. Although preliminary results using modest $(20 \mu \mathrm{m})$ core diameter Yb-doped fibers have shown that the photonic bandgap architecture can be advantageously used in singlepass amplifiers [13], singlemode amplification in few meter long pieces of very large core fibers is still to be demonstrated. Very recently, the selective doping of the core has proved very efficient in designing large-core singlemode fiber oscillators $[14,15]$. In [14], a 40- $\mu$ m core diameter Yb-doped BF has been designed, fabricated and operated singlemode in the continuous wave (cw) oscillation regime. In the context of femtosecond pulse amplifiers, Bragg fibers can also be engineered to obtain dispersion profiles that are not dominated by the material, and adjustable wavelenth guiding range, which might prove useful to optimize amplifier architecture or suppress stimulated Raman scattering.

In the present communication, we report on nearlydiffraction limited operation of $40 \mu \mathrm{m}$-core Bragg fibers in a femtosecond chirped pulse amplification laser system, allowing the generation of $47 \mathrm{~W}$ average power 500 
fs pulses at a repetition rate of $35 \mathrm{MHz}$. The opticalto-optical efficiency, beam spatial quality, and nonlinearity level in our experiments are in good agreement with expected performances given the core size and already comparable with current state-of-the-art total internal reflection-based fibers. This is to our knowledge the first report of a high power fs system based on photonic bandgap active fiber, and demonstrates the great potential of this technology for further energy scaling.

\section{Numerical modelling of amplification in the actual fiber}

Single-mode emission is an issue for very high power fiber lasers. Modeling the transverse spatial behavior of the Bragg fiber amplifier used in the CPA experiment is therefore important. For Bragg fiber amplifiers, such a modeling is not straightforward. On the one hand, Bragg fibers are known to be asymptotically single-mode, i.e. several modes can be excited and propagated over the fiber length but theses modes exhibit highly different confinement losses. Considering passive, single cladding Bragg fibers, if the fiber is long enough, the emitted beam can reach the criterion for being singlemode. Following the standard definition for singlemodedness, a fiber is said singlemode when one mode (usually the fundamental) carries more than $97.75 \%$ of the total propagated power [16]. On the other hand, in all double-clad fibers, this criterion cannot be easily applied for modeling as the mode electric field which is not well confined into the core is guided into the pump core and confinement loss are usually calculated to be almost zero. For this reason, modeling and qualifying the emitted beam implies to perform a full modeling of the whole amplifier taking into account the actual fiber refractive index profile, the actual pump scheme, the amplifier architecture and 3D-spatial distribution of gain. Indeed, for active LMA fibers, longitudinal and transverse gain distribution plays a role in the modal competition. For this reason, we first calculate the electric field distribution (and intensity) for all signal modes using the finite element method and the actual refractive index profile. Then, the modal competition behavior in amplifier can be accurately predicted taking into account all the parameters [17]. As Bragg fibers are known to be robust to bending, we paid in this section a particular attention to the impact of bending radius on the beam quality. The measured refractive index of the photonic bandgap fiber is shown in fig.1.

It is composed of a low- $n$ core, approximately 40$\mu \mathrm{m}$ in diameter $(D)$, surrounded by an alternation of high- $n$ and low- $n$ layers acting like a cylindrical Bragg mirror. The core is heavily doped with $\mathrm{Yb}^{3+}$ ions in its very center (the doped diameter is $D_{d}=16.6 \mu \mathrm{m}$ ). The Bragg fiber is coated in either a low- $n$ polymer or an air-clad (referred to as the polymer-clad (PCBF) or airclad (ACBF) Bragg fibers in the following), yielding a pump waveguide numerical aperture of 0.4 . The PCBF (ACBF) has 40/125 (40/160) $\mu \mathrm{m}$ core/clad diameters. 
For the PCBF, the small signal absorption of the core at the pump wavelength $(977 \mathrm{~nm})$ is approximately equal to $350 \mathrm{~dB} / \mathrm{m}$, corresponding to a cladding absorption of $5 \mathrm{~dB} / \mathrm{m}$. The mode field diameter (MFD) at $1 / \mathrm{e}^{2}$ in intensity is $26 \mu \mathrm{m}$. Not only the selective doping associated with the photonic bandgap guidance allows for singlemode operation in the straight fiber CW oscillator but also the bent fiber has proved singlemode down to a tight curvature radius $R_{b}=5 \mathrm{~cm}[11]$. For $\mathrm{Yb}^{3+}$ ions in a silica matrix, the fluorescence lifetime is approximately equal to $\tau=1 \mathrm{~ms}$. Consequently, the time dependency of the population inversion can be neglected for a repetition rate $f \geq \frac{10}{\tau}$, i.e. $f \geq 10 \mathrm{kHz}$. In our experiments, the CPA will be operated at $f \geq 100 \mathrm{kHz}$ so that the calculations can be carried out in the continuous wave regime. Then, we assumed a Gaussian excitation, parallel to the axis of the fiber, with a certain MFD smaller than the core diameter $(40 \mu \mathrm{m})$ and carrying an incident signal power $P_{0}$. The launching efficiency in each mode, defined as the ratio of the power in each fiber mode $P_{j}$ to $P_{0}$, has been computed [18] and shown in Fig. 2 for several configurations (from left to right: straight fiber, $R_{b}=13 \mathrm{~cm}$ and $\left.R_{b}=6.6 \mathrm{~cm}\right)$.

Regardless of the configuration, the launching efficiency in the $\mathrm{LP}_{01}$ mode is favored above higher-order modes. The $\mathrm{LP}_{01}$ launching efficiency peaks for an MFD of approximately $20 \mu \mathrm{m}$. This value differs from the $\mathrm{LP}_{01}$ MFD $(26 \mu \mathrm{m})$ due to the fact that the Bragg fibre mode is Bessel-like instead of Gaussian-like. Moreover, for the straight fiber the launching efficiency in even high-order modes is significant only for very small input MFDs of approximately $8 \mu \mathrm{m}$. On the contrary for a tighter bend radius $R_{b} \leq 10 \mathrm{~cm}$, the non-axisymmetric $\mathrm{LP}_{11}$ mode can be excited. This is due to the fact that the field distribution of the $\mathrm{LP}_{11}$ mode is dramatically distorted due to the curvature, thereby leading to a non-zero overlap between this mode and the input Gaussian-like one. In our first low-power experiment, the input signal beam MFD was characterized by $\mathrm{MFD}=20 \mu \mathrm{m}$ and $\mathrm{P}_{0}=190 \mathrm{~mW}$ while the pump power was fixed to $22 \mathrm{~W}$. Taking into account these experimental conditions, the rate equations have been solved in order to determine the output modal population $[19,17]$. Numerical results have been plotted in the bottom row of Fig. 2. For bend radii greater than $10 \mathrm{~cm}$, the output modal content can be considered as singlemode according to the definition in [16]. For a bend radius of $6.6 \mathrm{~cm}$, although the fiber is not strictly singlemode, $94 \%$ of the power is contained in the fundamental mode. The optical-to-optical efficiency for the $\mathrm{LP}_{01}$ mode is about $60 \%$ for a 3 -m long amplifier. As a conclusion, although not strictly speaking singlemode, the Bragg fiber can be operated in a large range of excitation conditions and bend radii with an essentially single transverse mode behavior.

\section{Experimental results}

Our setup, depicted in Fig. 3, consists in a femtosecond oscillator followed by a pulse picker, a stretcher, two am- 
plification stages and a compressor. The oscillator provides $190-\mathrm{fs}, 35-\mathrm{nJ}$ pulses at $1030 \mathrm{~nm}$ with a $6.5 \mathrm{~nm}$ spectrum FWHM. The repetition rate is $35 \mathrm{MHz}$, and can be reduced to $1 \mathrm{MHz}$ by an acousto-optic modulator (AOM). The selected pulses are stretched to 150 ps using a 1600 lines/mm grating, and pass through an optical isolator before being seeded to the first amplifier. Taking into account all the transmission coefficients (60\% for both the AOM and the stretcher, $85 \%$ for the isolator) the seeded pulse energy is $10 \mathrm{~nJ}$.

\subsection{Polymer-coated Bragg fiber}

The first amplifier stage is composed of a 1.9 m-long $\mathrm{PCBF}$. The second stage is a PCBF for low power experiments and an ACBF for the high power experiment since the ACBF can be pumped with a higher-power diode owing to the larger pump core and numerical aperture. No special care was taken to bend the fibers with a specific bending radius, and the average bending radius on the experiment for both fiber is around $10 \mathrm{~cm}$. The first amplification stage is pumped in a counter-propagative geometry by a fiber-coupled laser diode at $975 \mathrm{~nm}$ providing up to $30 \mathrm{~W}$ in a $200 \mu \mathrm{m}$ diameter fiber with numerical aperture (NA) equal to 0.22 . The output pulses go through a second isolator, on their way to the second amplifier. The PCBF piece used in the second amplifier is $2.8 \mathrm{~m}$-long, and is pumped by a fiber-coupled laser diode working at $975 \mathrm{~nm}$ and providing up to $35 \mathrm{~W}$ in a $100 \mu \mathrm{m}$ diameter fiber with NA 0.22. The ACBF piece is pumped by a fiber-coupled laser diode at $975 \mathrm{~nm}$ providing up to $400 \mathrm{~W}$ in a $400 \mu \mathrm{m}$ diameter fiber with NA 0.22. At the output of the second stage, the pulses are compressed with two 1600 lines/mm transmission gratings with an overall transmission of $57 \%$.

The first experiment was made with the PCBF at $35 \mathrm{MHz}$, to investigate the efficiency of the fiber. In this configuration, the first amplifier was not really used as it was simply pumped to provide $190 \mathrm{~mW}$ of average power at the entrance of the second stage. We show in Fig. 4a the output power extracted before compression, with respect to the pump power (measured just before injection in the fiber). The optical-to-optical efficiency was $50 \%$ in good quantitative agreement with the numerical results. The maximum average output power was $11.1 \mathrm{~W}$, obtained with $22 \mathrm{~W}$ of pump power, which corresponds to $6.3 \mathrm{~W}$ after compression. In Fig. $4 \mathrm{~b}$ is represented the output beam profile. We measured the $\mathrm{M}^{2}$ parameter in the $x$ and $y$ directions to be 1.11 and 1.13 respectively, indicating a nearly diffraction-limited amplified beam with an essentially Gaussian profile.

The temporal and spectral properties of the compressed pulses at maximum pump power are shown in Fig. 5a and 5b respectively. The autocorrelation trace exhibits a pulse duration of 345 fs, assuming a Gaussian temporal shape. This duration is in good agreement with the spectral width of $4.7 \mathrm{~nm}$ FWHM. The corresponding time-bandwidth product is 0.46 , which is very close to the Fourier-transform limit. A long range autocorre- 
lation on a time window of 50 ps showed no replica of the pulses, indicating that higher-order spatial modes, if present, are of negligible magnitude, as hinted to by the good measured spatial quality and the numerical simulations of previous paragraph. The Bragg fibers used in this experiment are not polarization-maintaining, but the polarization state of the output signal does not fluctuate under normal operation. The fiber output polarization state can therefore be adjusted with a quarter-wave plate and half-wave plate before the compressor, which is efficient for one linear polarization only. However we clearly observed power fluctuations that we related to polarization state evolutions when the fiber was intentionally mechanically disturbed. As mentionned in the introduction, polarization-maintaining Bragg fibers can be designed[11].

To investigate the level of nonlinearity and confirm the expected mode-field diameter of the fiber, we reduced the repetition rate of the pulse train down to 1 $\mathrm{MHz}$. In these conditions, the first amplifier was used to boost the average power from $12 \mathrm{~mW}$ to $200 \mathrm{~mW}$ at the input of the second stage and saturate it. The maximum output average power allowed with controllable impact from self-phase modulation was $4.2 \mathrm{~W}$ with 9.7 W of pump power. This corresponds to $2.4 \mathrm{~W}$ after the compressor, and $2.4 \mu \mathrm{J}$ output pulse energy. Fig. 6a and $6 \mathrm{~b}$ show respectively the autocorrelation trace and the spectrum without and with spectral clipping at the stretcher, at constant pulse energy, showing that spec- tral clipping allows us to generate relatively clean 456 fs pulses at this energy level. Indeed, spectral clipping can suppress spectral content exhibiting a spectral phase that is not well compensated by the compressor, thereby leading to cleaner pulses. Assuming a mode-field diameter of $26 \mu \mathrm{m}$, as obtained using finite-element calculations and experimentally measured, simulations based on the split-step Fourier method were used to estimate the B-integral to be $10.1 \mathrm{rad}$ in this case. The performance limitations in terms of nonlinearity are therefore in agreement with the expected mode field diameter of the Bragg guiding structure. The current state of the art in terms of obtainable pulse energy in fiber CPA systems is much higher[20], and the results obtained here constitute a proof-of-concept result. However, energy scaling is possible by using a larger stretching ratio, exploring further scaling of the core diameter, and optimizing pulse shape and CPA architecture to reduce the impact of nonlinear effects, as was done in previous research work.

\subsection{Air-clad Bragg fiber}

Since the output power value was pump power-limited in the first experiment, we also tried to use an ACBF in the second stage: the use of a different pump power guiding mechanism (air clad) allowed us to pump with more powerful diodes. We used a 1.9 m-long piece of ACBF, and operated the system at $35 \mathrm{MHz}$ to investigate the maximum average power. The first amplification stage was used to provide $2.5 \mathrm{~W}$ of average power at the input of 
the second stage. The output power is plotted as a function of pump power in Fig. 4b. The maximum output power in this case was $82 \mathrm{~W}$, obtained for $300 \mathrm{~W}$ pump power, which led to $47 \mathrm{~W}$ average power after compression (1.3 $\mu \mathrm{J}$ compressed pulse energy). This relatively low efficiency is due to non-optimal pump coupling into the fiber, and to pump absorption saturation. Figure 7a shows the pulse autocorrelation, showing a pulsewidth of 497 fs under the Gaussian shape assumption, and Fig.

$7 \mathrm{~b}$ displays the corresponding spectrum.

The spectrum was broadened to $7.5 \mathrm{~nm}$ FWHM due to the onset of self-phase modulation. The B-integral for this system was evaluated to be $4.8 \mathrm{rad}$. This value is lower than in the case of the $1 \mathrm{MHz}$ repetition rate above, although the spectral broadening is slightly higher $(7.5$ $\mathrm{nm}$ instead of $6 \mathrm{~nm}$ ). A slight difference in the effective areas for the $\mathrm{ACBF}$ and $\mathrm{PCBF}$ might explain this result. Indeed, due to imperfections in the fiber fabrication process, the output beam exhibits a slight depression in the center as shown in Fig. 4b, yielding a measured $\mathrm{M}^{2}$ value of 1.36 and 1.5 for the $x$ and $y$ directions respectively. The non-ideal output mode shape is solely due to the imperfect index profile, and does not change as the pump power is increased.

\section{Conclusion}

In conclusion, we have demonstrated the first use of Ytterbium-doped $40 \mu \mathrm{m}$ core double-clad photonic bandgap Bragg fiber in a femtosecond CPA system. The achieved optical-to-optical efficiency can be as high as $50 \%$, and is comparable to values obtained using well-established fiber technologies. The performance in terms of pulse energy for this moderately-stretched CPA system is in good agreement with an expected mode field diameter of $26 \mu \mathrm{m}$, confirming the great potential for further core size scaling. An air-clad Bragg fiber was used to demonstrate amplification up to $47 \mathrm{~W}$ of average power after compression. The benefits of the Bragg fiber technology in terms of ease of manipulation, bending sensitivity, potential dispersion control, and scaling of the core size, make this technology a serious candidate for future high power fiber femtosecond systems. The authors acknowledge the financial support of the Agence Nationale de la Recherche through grant ANR 06 BLAN-0091-01 HiPoLYFF.

\section{References}

1. T. Eidam, S. Hanf, E. Seise, T. V. Andersen, T. Gabler, C. Wirth, T. Schreiber, J. Limpert, and A. Tunnermann, Opt. Lett. 35, 94-96 (2010).

2. M. Hanna, D. Papadopoulos, F. Druon, and P. Georges, Opt. Exp. 17, 10835-10840 (2009).

3. D. Strickland and G. Mourou, Opt. Comm. 55, 447-449 (1985).

4. J. Limpert, A. Liem, M. Reich, T. Schreiber, S. Nolte, H. Zellmer, A. Tunnermann, J. Broeng, A. Petersson, and C. Jakobsen, Opt. Express 12, 1313-1319 (2004).

5. F. Di Teodoro and Northrop Grumman Aerospace Systems (United States), in Photonics West, San Francisco, 
California, United States, 23 - 28 January 2010, Paper 7580-5.

6. A. Argyros, T. A. Birks, S. G. Leon-Saval, C. B. Cordeiro, F. Luan, and P. St. J. Russell, Opt. Express 13, 309-314 (2005).

7. V. Pureur, L. Bigot, G. Bouwmans, Y. Quiquempois, M. Douay, and Y. Jaouen, Appl. Phys. Lett. 92, 061113 (2008).

8. A. Shirakawa, H. Maruyama, K. Ueda, C. B. Olausson, J. K. Lyngs, and J. Broeng, Opt. Express 17, 447-454 (2009). 9. S. Février, R. Jamier, J.-M. Blondy, S. L. Semjonov, M. E. Likhachev, M. M. Bubnov, E. M. Dianov, V. F. Khopin, M. Y. Salganskii, and A. N. Guryanov, Opt. Express 14, 562-569 (2006).

10. Yu. A. Uspenskii, E. E. Uzorin, A. V. Vinogradov, M. E. Likhachev, S. L. Semjonov, M. M. Bubnov, E. M. Dianov, R. Jamier, and S. Février, Opt. Lett. 32, 1202-1204 (2007).

11. M. E. Likhachev, A. D. Pryamikov, D. A. Gaponov, M. M. Bubnov, M. Y. Salganskii, V. F. Khopin, A. N. Guryanov, and S. Février, Opt. Lett. 34, 1366-1368 (2009). 12. R. Jamier, S. Février, G. Humbert, M. Devautour, P. Viale, J.-M. Blondy, S. L. Semjonov, M. E. Likhachev, M. M. Bubnov, E. M. Dianov, V. F. Khopin, M. Y. Salganskii, and A. N. Guryanov, Proc. SPIE 6588, 658805 (2007).

13. D. A. Gaponov, S. Février, P. Roy, M. Hanna, D. N. Papadopoulos, L. Daniault, F. Druon, and P. Georges, in Conference on Lasers and Electro-Optics, OSA Technical Digest (CD) (Optical Society of America, 2010), paper CWC1.

14. D. A. Gaponov, S. Février, M. Devautour, P. Roy, M. E. Likhachev, S. S. Aleshkina, M. Y. Salganskii, M. V. Yashkov, and A.N. Guryanov, Opt. Lett. 35, 2233-2235 (2010).
15. J. R. Marciante, R. G. Roides, V. V. Shkunov, and D.

A. Rockwell, Opt. Lett. 35, 1828-1830 (2010).

16. CEI/IEC International standard 793-1-C7A, "cutoff wavelength measurement for single-mode fibre".

17. M. Devautour, PhD thesis, University of Limoges (2009). 18. A. W. Snyder and J. D. Love, "Optical waveguide theory", Section 20, Chapman and Hall (London), 1984.

19. Z. Jiang and J. R. Marciante, J. Opt. Soc. Am. B 25, 247 (2008).

20. F. Roser, T. Eidam, J. Rothhardt, O. Schmidt, D. N. Schimpf, J. Limpert, and A. Tunnermann, Opt. Lett. 32, 3495-3497 (2007). 


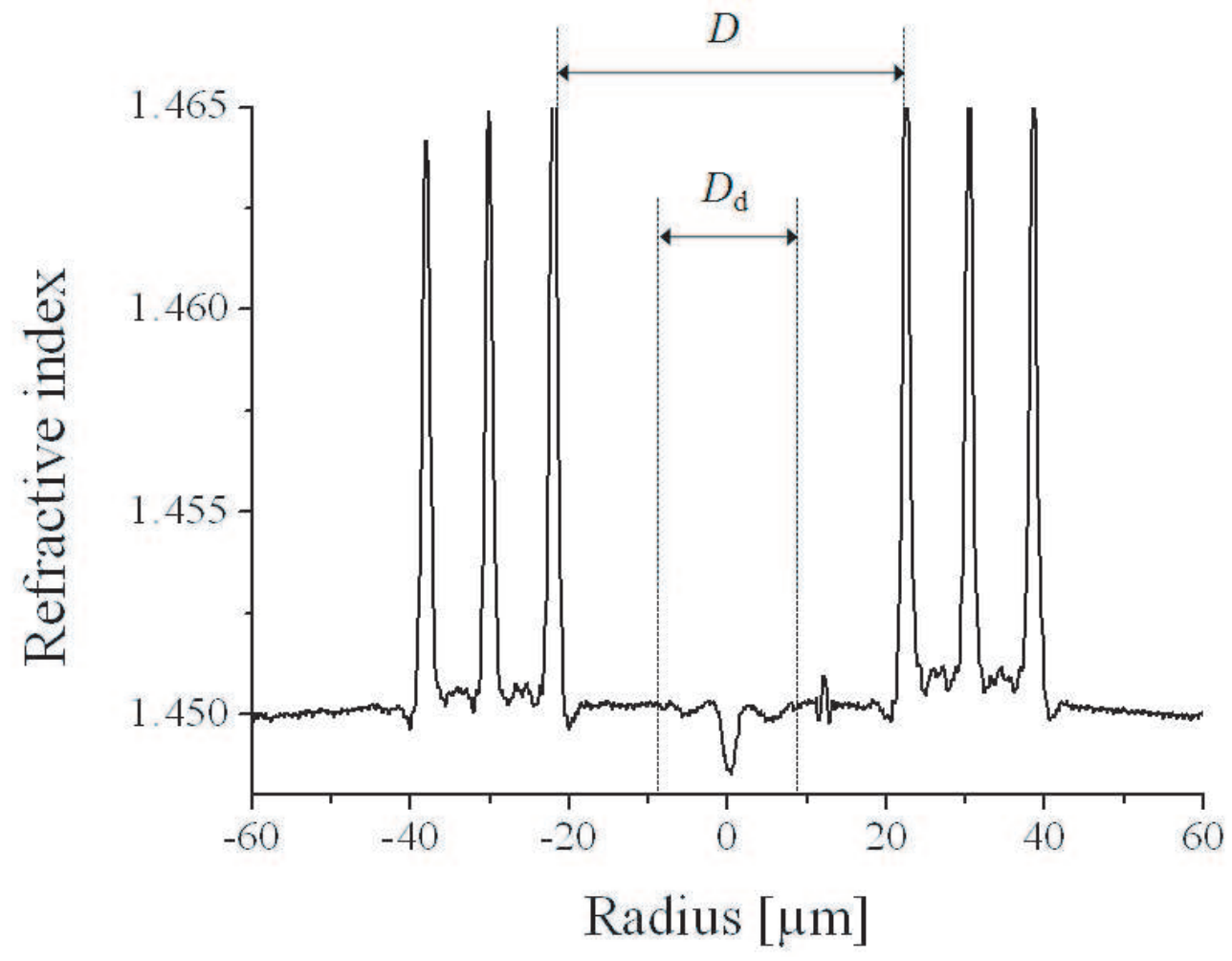

Fig. 1 Refractive index profile of the fiber used.
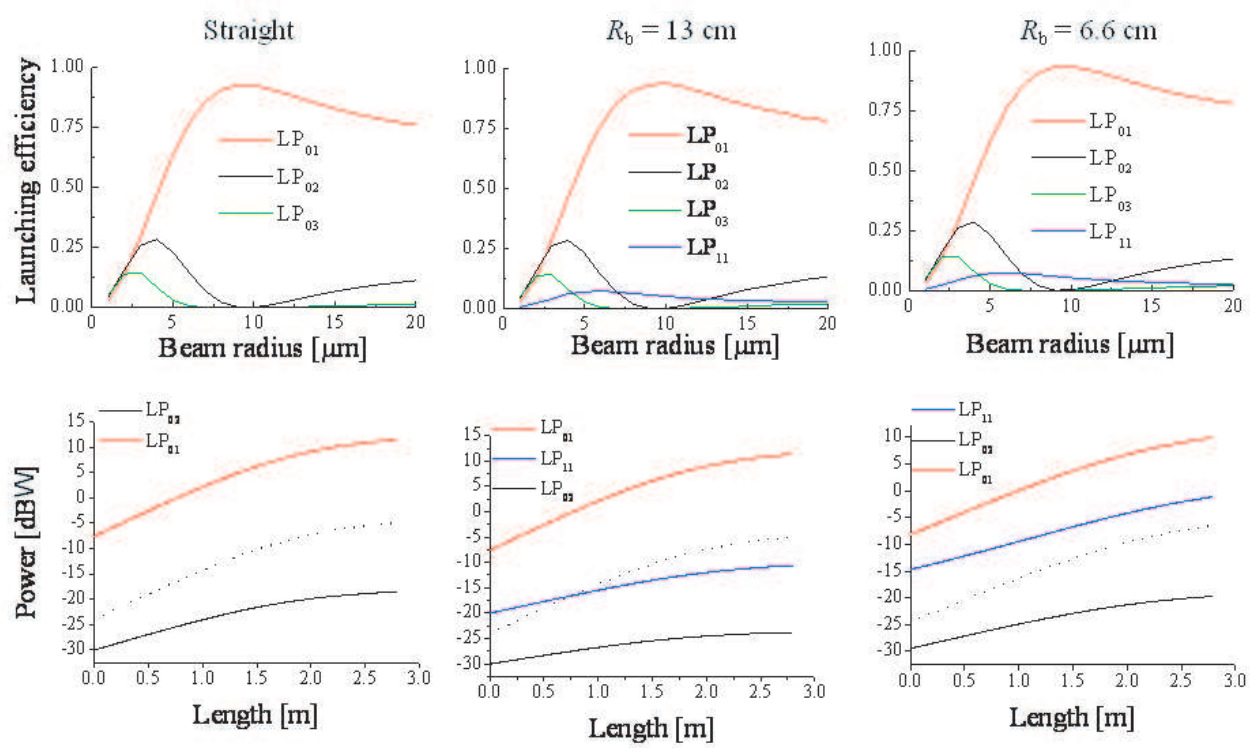

Fig. 2 First row: computed modal launching efficiency versus the input mode field radius for several bend radii. From left to right: straight fiber, $R_{b}=13 \mathrm{~cm}$ and $R_{b}=6.6 \mathrm{~cm}$. Second row: longitudinal evolution of the modal power in logarithmic scale for the same curvature radii and input MFD $=20 \mu \mathrm{m}$. The dashed line represents the definition of singlemodedness. The pump power is $22 \mathrm{~W}$. The signal power $\mathrm{P}_{0}=190 \mathrm{~mW}$. 


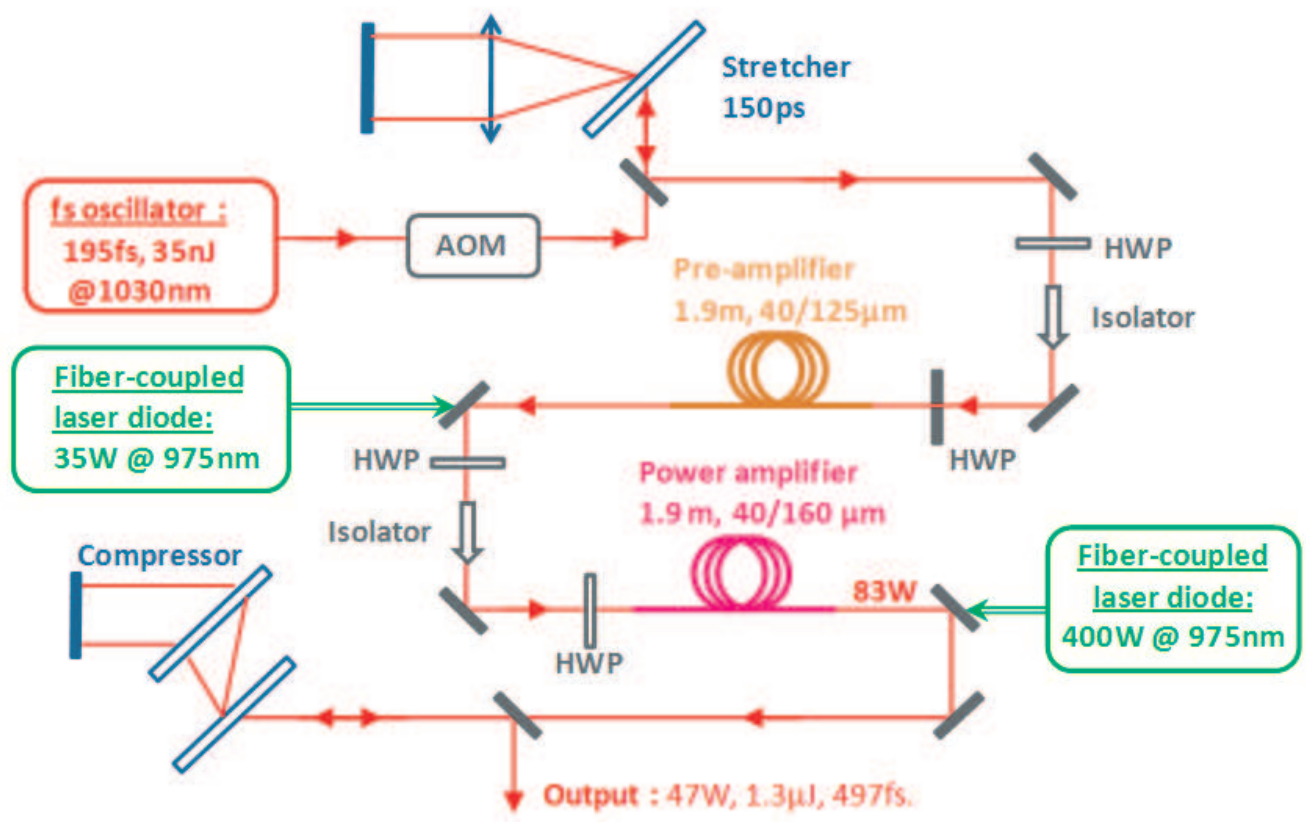

Fig. 3 Experimental setup for the high power laser source using ACBF. AOM: Acousto-Optic Modulator; HWP: Half-Wave Plate.
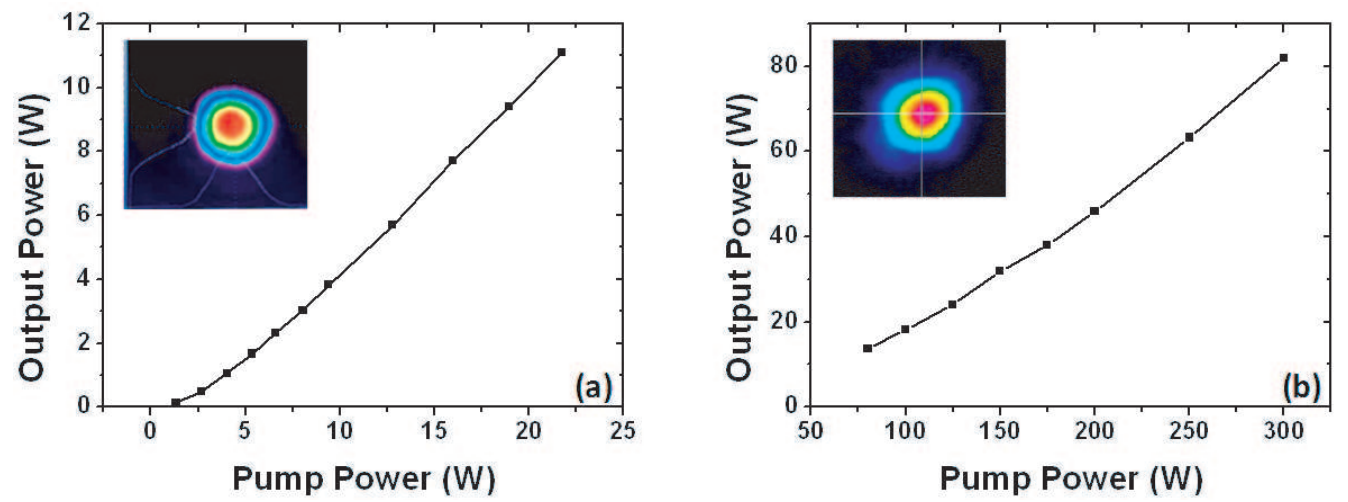

Fig. 4 (a) Output power from the PCBF as a function of pump power. Insert: spatial beam profile at maximum power. (b) Output power from the $\mathrm{ACBF}$ as a function of pump power. Insert: spatial beam profile at maximum power. 

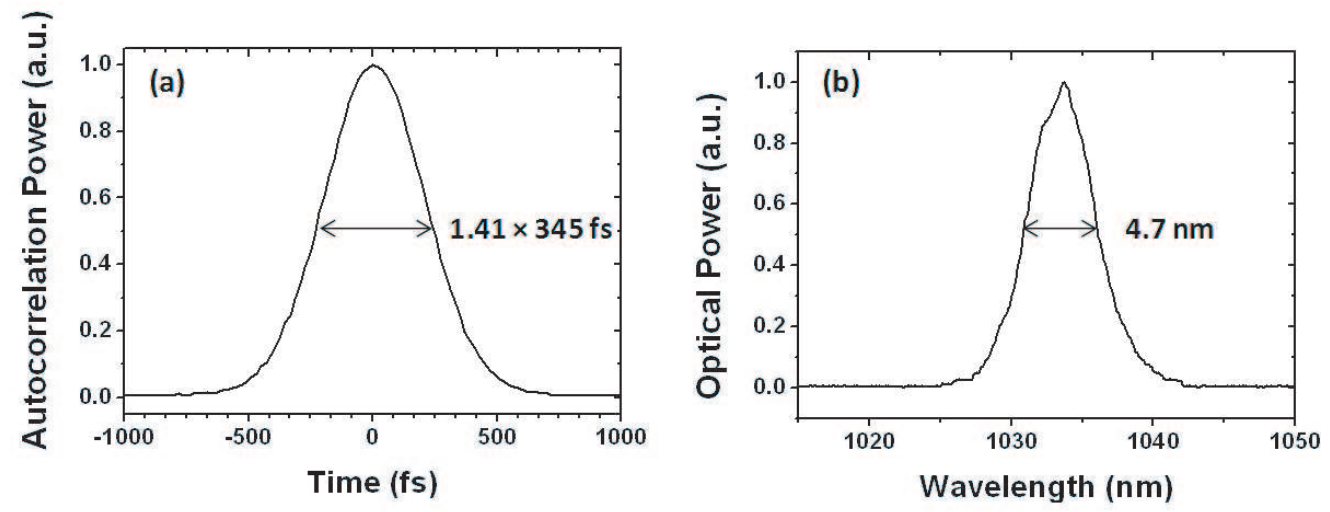

Fig. 5 (a) Autocorrelation trace for the $\mathrm{PCBF}$ at $35-\mathrm{MHz}$ repetition rate and compressed average power of $6.3 \mathrm{~W}$. (b) Corresponding spectrum.
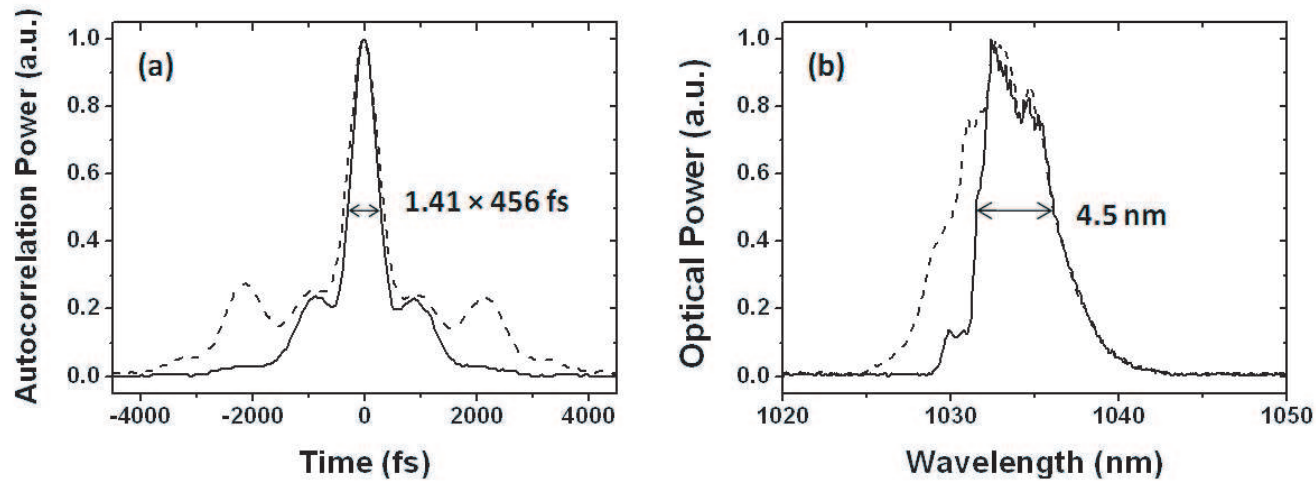

Fig. 6 (a) Autocorrelation traces for the PCBF at 1-MHz repetition rate for a compressed pulse energy of $2.4 \mu \mathrm{J}$, without (solid curves) and with (dashed curves) spectral clipping at the stretcher. (b) Corresponding spectra.
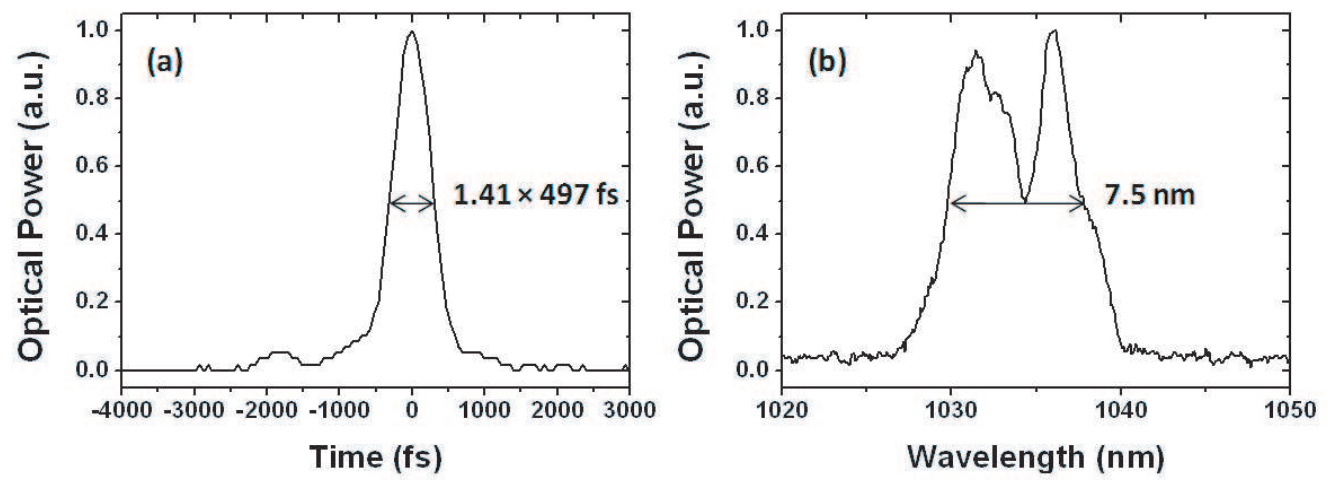

Fig. 7 (a) Autocorrelation trace for the ACBF at $43 \mathrm{~W}$ of compressed average power (b) Corresponding spectrum. 